\title{
Subjective recovery from pregnancy-related pelvic girdle pain the first 6 weeks after delivery: a prospective longitudinal cohort study
}

\author{
Anne Marie Gausel ${ }^{1} \cdot$ Stefan Malmqvist ${ }^{2,3} \cdot$ Knut Andersen $^{2} \cdot$ Inger Kjærmann $^{2} \cdot$ Jan Petter Larsen $^{4} \cdot$ Ingvild Dalen $^{5}$. \\ Inger Økland ${ }^{1}$
}

Received: 23 August 2019 / Revised: 6 December 2019 / Accepted: 4 January 2020 / Published online: 16 January 2020

(C) The Author(s) 2020

\begin{abstract}
Purpose The purpose of this study was to investigate the subjective recovery from pregnancy-related pelvic girdle pain (PGP) during the first 6 weeks after delivery and to detect possible risk factors for a poor recovery.

Methods The participants were included in this study at the routine ultrasound examination at 18 weeks of pregnancy. The women received a weekly SMS with the question "How many days during the last week has your PGP been bothersome?" The SMS-track from the final 10 weeks of pregnancy and first 6 weeks after delivery were assessed and sorted, based on individual graphs. A total of 130 women who reported PGP during pregnancy and met for clinical examination 6 weeks after delivery were included in the study.

Results In all, 83\% of the women experienced substantial recovery from severe or moderate PGP within 6 weeks after delivery. Of these, $44 \%$ reported a substantial recovery already within 2 weeks after delivery. More multiparous women, women reporting PGP the year before pregnancy, and women with high pain intensity during pregnancy had a poor recovery. Conclusions The prognosis following PGP in pregnancy is good and the majority of women recovered substantially from severe and moderate pregnancy-related PGP within 6 weeks after delivery. For many women, a subjective substantial recovery occurred within 2 weeks after delivery. Predictors for a poor recovery were multiparity, PGP the year before pregnancy and a high pain intensity during pregnancy.
\end{abstract}

\section{Graphic abstract}

These slides can be retrieved under Electronic Supplementary Material.
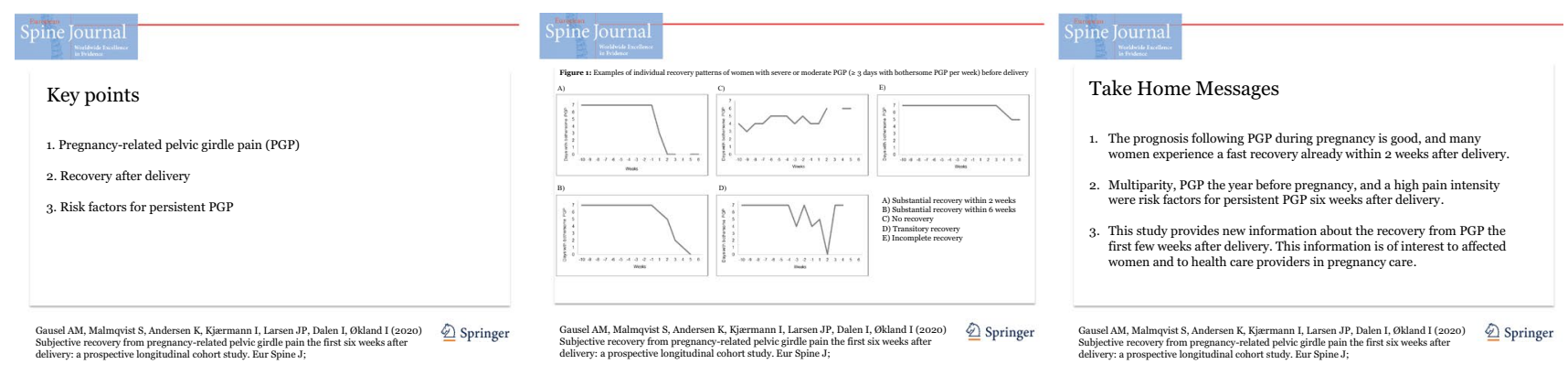

Keywords Pelvic girdle pain $\cdot$ Pregnancy $\cdot$ Persistent $\cdot$ Recovery $\cdot$ Risk factors

Electronic supplementary material The online version of this article (https://doi.org/10.1007/s00586-020-06288-9) contains supplementary material, which is available to authorized users.

Anne Marie Gausel

anne.marie.gausel@sus.no; amgausel@hotmail.com

Extended author information available on the last page of the article

\section{Introduction}

Musculoskeletal pelvic girdle pain (PGP) during pregnancy is a common condition [1-3]. The exact prevalence is difficult to assess due to inconsistent definitions of PGP and the lack of clinical testing. Depending on the 
definition, the prevalence of pain in the lumbopelvic area during pregnancy ranges from $4-90 \%$ in various studies. This indicates many different ways to measure and define this condition [4-6].

The European guidelines for the diagnosis and treatment of PGP from 2008 define PGP as "pain experienced between the posterior iliac crest and the gluteal fold, particularly in the vicinity of the sacroiliac joints. The pain may radiate in the posterior thigh and can also occur in conjunction with/or separately in the symphysis. The endurance for standing, walking, and sitting is diminished" [5]. Although the guidelines exclude lumbar causes of pain for the PGP diagnosis, many pregnant women experience low back pain (LBP), exclusively or in addition to pain in the pelvic area. The consequences of PGP vary, from only minor pain and disability to severe pain, disability, reduced quality of life and absence from work. Overall, the etiology of PGP is poorly understood, and so are the reasons why some women recover and some women do not.

Although most women recover from PGP within 6 months after delivery [7-9], some women experience years of intermittent or persistent PGP affecting their daily life activities, ability to work and quality of life [10-15]. We have previously shown that $16 \%$ of women reporting musculoskeletal pelvic pain (PP) during pregnancy were found to have persistent PGP 3-6 months after delivery, and that the risk factors for persistent pain were age 30 years and above, both PP and LBP during pregnancy, and moderate or high disability measured by Oswestry Disability Index (ODI) during pregnancy [16].

Researchers have investigated the recovery from PGP one or several months after delivery, but to our knowledge, there are no studies investigating the subjective recovery from PGP the very first weeks after delivery. Moreover, women with persistent PGP after birth want more information about the course of PGP and the factors influencing recovery [11]. Women with recurrent or continuous PGP after delivery have increased risk of future sick leave and disability [10, 14].

The use of automated text messaging and mobile phones has previously been used to describe recovery patterns [17], and short message service (SMS) is a lowkey method that requires little effort from the participants. Also, most people check their mobile phones regularly, which limits memory decay. Women who have just given birth are in a stressful situation, and to answer an SMS may be more feasible than to fill in a traditional questionnaire, answer a phone call, or to meet for an interview or a clinical examination.

The aim of this study was, by means of a weekly SMS question, to investigate the subjective recovery from pregnancy-related PGP the first 6 weeks after delivery and to detect possible risk factors for a poor recovery.

\section{Methods}

\section{Study design and study population}

This is an SMS-based, prospective, longitudinal cohort study of women during the final 10 weeks of pregnancy and the first 6 weeks after delivery. The women were included in the study at the routine ultrasound examination at 18 weeks of pregnancy at Stavanger University Hospital, Norway, from March to June 2010 [18].

Inclusion criteria were a low-risk singleton pregnancy and comprehension of the Norwegian language. All women, both symptomatic and asymptomatic, were asked to sign an informed consent. They were followed from pregnancy week 18 until 6 weeks after delivery with weekly, automated text messages (SMS-track). Women that reported pain in the pelvic area at or beyond 18 weeks were invited to undergo a clinical examination and fill in questionnaires at 18 and 30 weeks of pregnancy, and 6 weeks after the ultrasound estimated date of delivery (EDD).

The prospective longitudinal cohort study recruited 506 symptomatic and asymptomatic women at 18 weeks of pregnancy. In this substudy, we included the symptomatic women who reported PGP and who met for the clinical examination 6 weeks $(n=130)$ after delivery. To be able to sort the SMS data into pre- and post-delivery, the actual date of delivery was registered at the clinical examination 6 weeks after EDD.

\section{Questionnaires}

At 18 weeks of pregnancy, all women filled in a questionnaire on demographic information. In addition, the women reporting pain in the pelvic area answered questionnaires on previous illnesses and treatments, workload, possible comorbidities, current symptoms, pain location, duration of pain and sick leave. The intensity of PGP was retrospectively reported using a numeric rating scale (NRS) where the women were asked to report the average level of PGP in the previous trimester. In this study, the scale ranged from 0 to 100 , and score 0 was described as "No pain" and 100 as "Unbearable pain." The questionnaires with information on current symptoms, pain location, duration of pain and sick leave were repeated at 30 weeks of pregnancy and 6 weeks after delivery.

\section{SMS-track}

Every Sunday, the women were asked in an SMS: "How many days during the last week has your pelvic pain been bothersome?" If there was no reply, the question was 
repeated $24 \mathrm{~h}$ later. The question should be answered with one single number between 0 and 7 , and the response was automatically entered into a database, where continuous information from each woman was saved.

\section{Analyses of data}

The SMS-track from 10 randomly selected women was assessed by two of the authors. The individual pain patterns were visualized in graphs, including the final 10 weeks of pregnancy and the first 6 weeks after delivery. From a clinical perspective, a first proposal for grouping was agreed on. Then, three authors individually investigated and sorted the pain patterns into the different groups. The 120 different graphs were assessed by these authors together, resulting in a revised set of subgroups. A new assessment was then done individually, blinded to the initial decisions. Thereafter, in a final meeting, a consensus for all 120 graphs was reached. The subgroups are defined and presented in Box 1 , and examples of individual pain patterns are given in Fig. 1.

Proportions of women with substantial recovery and women with either no, transitory, or incomplete recovery are presented as percentages and $95 \%$ confidence intervals (CI), estimated using the online statistical calculator at http:vassarstats.net. Demographic and clinical features are given as means and standard deviations (SDs), and as counts and percentages. Women with substantial recovery were compared with women with either no, transitory, or incomplete recovery, using independent samples $t$ test for continuous data, and Chi-squared test for proportions. A generalized estimating equations (GEE) analysis was used for an overall comparison of pain intensity (NRS) between women with substantial recovery and women with a poor recovery throughout the whole pregnancy. A $p$ value $\leq 0.05$ was considered statistically significant, and statistical analyses were performed in IBM SPSS Statistics Version 24.

\section{Results}

In all, 130 women met for the clinical examination 6 weeks after EDD. However, 10 women lacked information on when the SMS-track started, resulting in 120 women eligible for further assessment. Seventy-six women reported a high number of days $(\geq 5)$ with bothersome PGP per week before delivery and were categorized as having severe PGP; see Table 1. Another 18 women reported on average $\geq 3$ days per week of bothersome PGP, and were categorized with moderate PGP.

In all, 21 women had on average less than 3 days of bothersome PGP per week the final 10 weeks before delivery. Another five women did not respond, or responded irregularly, to the weekly SMS before delivery, and were categorized as missing. These 26 women are not included in the statistical analyses.

The response rate to the SMS question was on average $89 \%$ the final 10 weeks before delivery. After delivery, the response rate dropped week by week from $71 \%$ (week 1) to $43 \%$ (week 6) (Fig. 2).

Of the 94 women with severe or moderate PGP before delivery, we had valid information after delivery on 76 women. 83\% (63 of 76) (95\% CI 73-90\%) reported a substantial recovery from PGP after delivery. Of these, $44 \%$ (28 of 63) (95\% CI 33-57\%) responded with 0 days of bothersome PGP per week within 2 weeks after delivery. The remaining had a slower or more intermittent recovery pattern, but reached our definition of substantial recovery from PGP within 6 weeks after delivery.

Demographic and clinical features for the women with substantial recovery $(n=63)$ and women with either no, transitory, or incomplete recovery $(n=13)$ are shown in Table 2. For most variables, there was no statistically significant difference between the two groups. More than

Box 1 Subgrouping before and after delivery

\begin{tabular}{lc}
\hline Before delivery (10 weeks) & After delivery (6 weeks) \\
\hline Severe PGP & Substantial recovery \\
Persistent 6 or 7 days with bothersome PGP per week. Included in & 0,1 , or 2 days with bothersome PGP per week within the first 6 weeks \\
this group was also women with increasing number of days the last & after delivery. If 0 was never reported, 1 or 2 days with bothersome \\
3 weeks before delivery (average $\geq 5$ days), and women with decreas- & PGP had to be registered twice within 6 weeks \\
ing number of days the last 3 weeks before delivery & Poor recovery \\
Moderate PGP & No or transitory recovery \\
Intermittent or moderate number of days with bothersome PGP per & No reduction or initial decrease in number of days, but before week 6 \\
week, average $\geq 3$ days & increasing number of days with bothersome PGP per week \\
No or mild PGP & $\begin{array}{c}\text { Incomplete recovery } \\
\text { Average }<3 \text { days of bothersome PGP per week before delivery }\end{array}$ \\
Missing data & Reduction in number of days with bothersome PGP per week, but not \\
Not possible to classify due to completely or partially missing data & Missing data \\
& Not possible to classify due to completely or partially missing data \\
\hline
\end{tabular}

$P G P$ pelvic girdle pain 
(A)

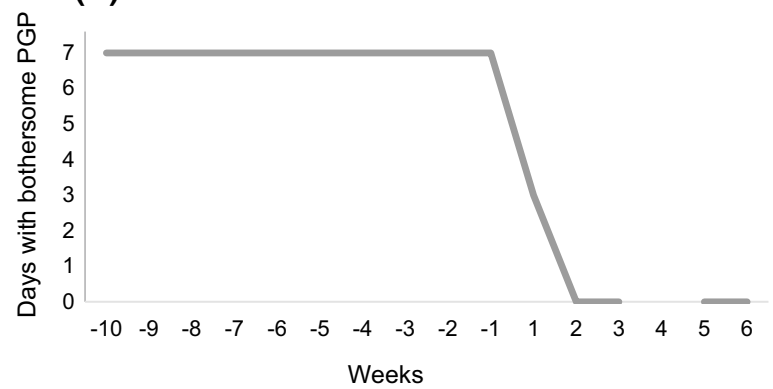

(B)

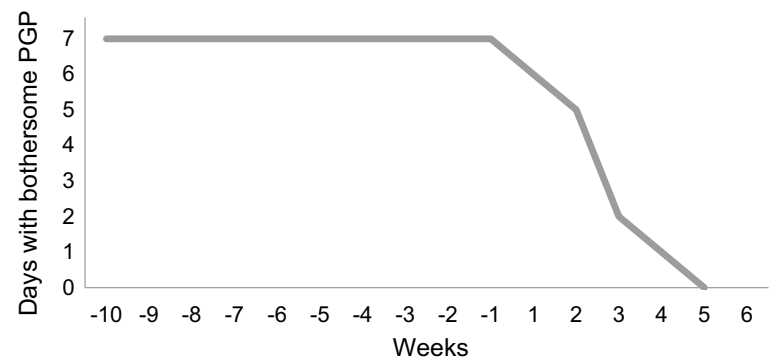

(C)

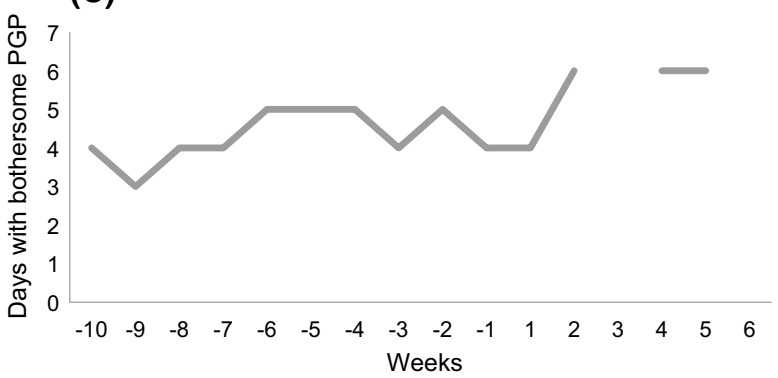

(D)

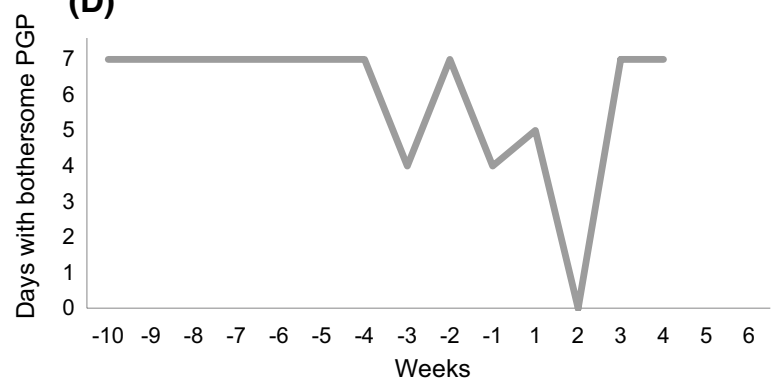

(E)

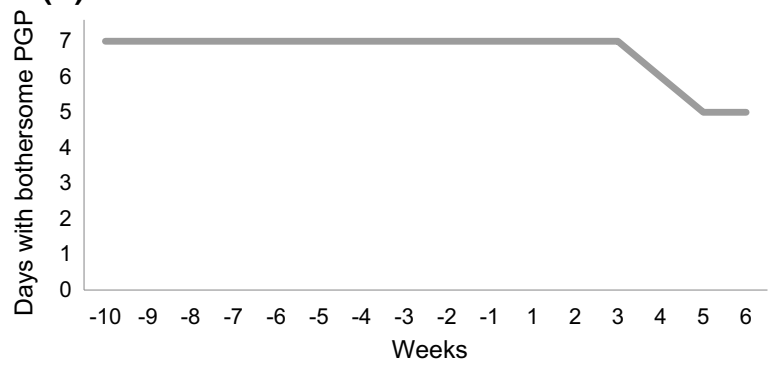

Fig. 1 Examples of individual recovery patterns of women with severe or moderate PGP ( $\geq 3$ days with bothersome PGP per week) before delivery. a Substantial recovery within 2 weeks. b Substantial recovery within 6 weeks. c Norecovery. d Transitory recovery. $\mathbf{E}$ Incomplete recovery
Table 1 Overview of women in categories after delivery by categories before delivery, excluding women with inadequate SMS-track and women with mild or no PGP before delivery

\begin{tabular}{lll}
\hline & $\begin{array}{l}\text { Severe PGP } \\
\text { before delivery }\end{array}$ & $\begin{array}{l}\text { Moderate PGP } \\
\text { before delivery }\end{array}$ \\
\hline Total, $n$ & 76 & 18 \\
Substantial improvement, $n(\%)$ & $49(65)$ & $14(78)$ \\
No or transitory recovery, $n(\%)$ & $4(5)$ & $1(6)$ \\
Incomplete recovery, $n(\%)$ & $6(8)$ & $2(11)$ \\
Missing, $n(\%)$ & $17(22)$ & $1(6)$ \\
\hline
\end{tabular}

$P G P$ pelvic girdle pain

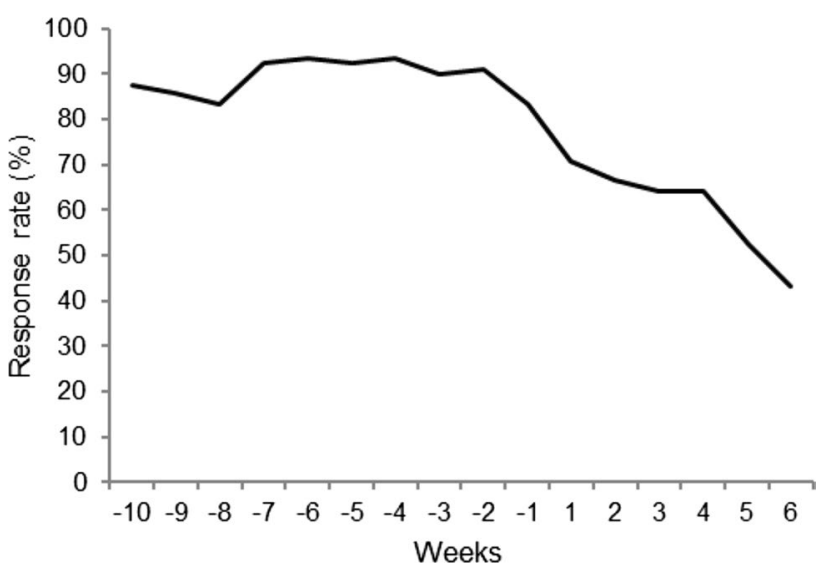

Fig. 2 Response rate to the weekly SMS question

$50 \%$ of the women were 30 years or older at inclusion in the study, and the majority of women had more than 12 years of education. More women in the substantial recovery group were primiparous, $37 \%$ versus $8 \%$ in the poor recovery group, and 1 out of 4 women had experienced depression in the beginning of pregnancy or before 30 weeks of pregnancy. Before pregnancy, 1 out of 4 women exercised regularly, but once pregnant, the number of women dropped to $0-10 \%$. Many women had experienced PGP in previous pregnancies and the majority of women (85\%) reported having LBP in addition to PGP.

Two variables were statistically significantly different between the two groups. First, more multiparous women experienced no, transitory, or incomplete recovery compared with primiparous women $(p=0.042)$. Second, women who reported PGP the year before pregnancy were found to have insufficient recovery compared with women who reported no PGP the year before $(p=0.047)$.

Figure 3 shows the retrospectively reported pain intensity due to PGP, as reported in questionnaires at 18 and 30 weeks of pregnancy and 6 weeks after delivery. Women with either no, transitory, or incomplete recovery reported 
Table 2 Demographic and clinical features among women with substantial recovery $(n=63)$, and women with no, transitory, or incomplete recovery $(n=13)$

\begin{tabular}{|c|c|c|c|}
\hline Variables & $\begin{array}{l}\text { Substantial recovery } \\
(n=63)\end{array}$ & $\begin{array}{l}\text { Poor recovery } \\
(n=13)\end{array}$ & $p$ \\
\hline Age at 18 weeks of pregnancy, years & $30.4(4.7)$ & $32.1(4.6)$ & 0.24 \\
\hline Age $\geq 30$ years, $n(\%)$ & $35(56)$ & $8(62)$ & 0.69 \\
\hline Education length, years & $14.9(2.7)^{n=61}$ & $15.4(1.9)$ & 0.48 \\
\hline More than 12 years education, $n(\%)$ & $53(84)$ & $13(100)$ & 0.17 \\
\hline Heavy workload $^{\mathrm{a}}, n(\%)$ & $16(25)$ & $2(15)$ & 0.44 \\
\hline BMI before pregnancy & $24.9(5.4)$ & $22.9(3.8)$ & 0.22 \\
\hline BMI at 18 weeks of pregnancy & $26.4(4.6)^{n=61}$ & $24.9(4.1)$ & 0.28 \\
\hline Primiparous, $n(\%)$ & $23(37)$ & $1(8)$ & 0.042 \\
\hline Depressed during pregnancy up to 18 weeks ${ }^{\mathrm{b}}, n(\%)$ & $14(23)^{n=61}$ & $3(23)$ & 0.99 \\
\hline Depressed during pregnancy up to 30 weeks ${ }^{\mathrm{b}}, n(\%)$ & $14(26)^{n=53}$ & $3(23)$ & 0.81 \\
\hline Exercise before pregnancy ${ }^{\mathrm{c}}, n(\%)$ & $15(25)^{n=60}$ & $2(23)$ & 0.88 \\
\hline Exercise in pregnancy up to 18 weeks $^{\mathrm{c}}, n(\%)$ & $6(10)^{n=61}$ & $0(0)$ & 0.24 \\
\hline Exercise in pregnancy up to 30 weeks $^{\mathrm{c}}, n(\%)$ & $5(10)^{n=51}$ & $1(8)$ & 0.82 \\
\hline PGP in previous pregnancies, $n(\%)$ & $29(58)^{n=50}$ & $9(75)^{n=12}$ & 0.28 \\
\hline PGP in the year before pregnancy, $n(\%)$ & $12(20)$ & $6(46)$ & 0.047 \\
\hline PGP and LBP in pregnancy up to 18 weeks, $n(\%)$ & $52(84)^{n=62}$ & $11(85)$ & 0.95 \\
\hline \multicolumn{4}{|l|}{ Pregnancy length at delivery, weeks } \\
\hline Mode of delivery & & & 0.26 \\
\hline Spontaneous vaginal delivery & $41(68)^{n=60}$ & $9(75)^{n=12}$ & \\
\hline Operative vaginal delivery (forceps or vacuum) & $9(15)^{n=60}$ & $3(25)^{n=12}$ & \\
\hline Cesarean section & $10(17)^{n=60}$ & $0(0)^{n=12}$ & \\
\hline
\end{tabular}

The number of available women is indicated for the variables where data is missing. The results are given as means (SD) and counts (percentages)

$S D$ standard deviation, $B M I$ body mass index, $L B P$ low back pain

${ }^{a}$ Quite/very heavy work

${ }^{\mathrm{b}}$ Depressed: sometimes, often, always

${ }^{\mathrm{c}}$ At least 2-3 times per week overall statistically significant higher pain intensity throughout the whole pregnancy $(p=0.026)$.

\section{Discussion}

In this study, $83 \%$ of the women that reported severe or moderate PGP during the final 10 weeks before delivery experienced a substantial recovery within 6 weeks after delivery. Of these, $44 \%$ reported 0 days of bothersome PGP per week already within 2 weeks after delivery. Risk factors for a poor recovery were found to be multiparity and PGP the year before pregnancy. Also, women reporting a high pain intensity for PGP on the NRS scale during pregnancy experienced a poor recovery.

To our knowledge, this is the first study to investigate pregnancy-related PGP week by week before and after delivery. Other studies investigating persistent PGP have collected data several weeks, months, or years after delivery. Our data support the findings of Albert et al. [7], where the majority of women experienced recovery from PGP within 1 month after delivery. In addition, we find that for many women a full recovery occurs within 2 weeks after giving birth.

The SMS question investigates number of bothersome days with PGP. Dunn et al. [19] studied the concept bothersome, and they found that a single bothersomeness question was a valid measure of LBP severity, as it correlates with pain, disability, and psychological health. The SMS question including bothersome days the last week was also used by Axén et al. [17] in a LBP study, and they discussed the use of 2 days or less with bothersome LBP per week as a clinically sensible option for recovery.

The weekly SMS data collection is a strength of this study, and the response rate to the SMS question before delivery was close to $90 \%$. However, after delivery, the response rate gradually dropped. We speculate that a reason for this is the exposed situation the women are in, with a newborn infant and life-changing situation. Another reason might be that the women who experienced a fast recovery abstained from answering the SMS question because they 
Fig. 3 Pain intensity (NRS) during pregnancy for women with substantial recovery (dark gray) and women with poor recovery (light gray)

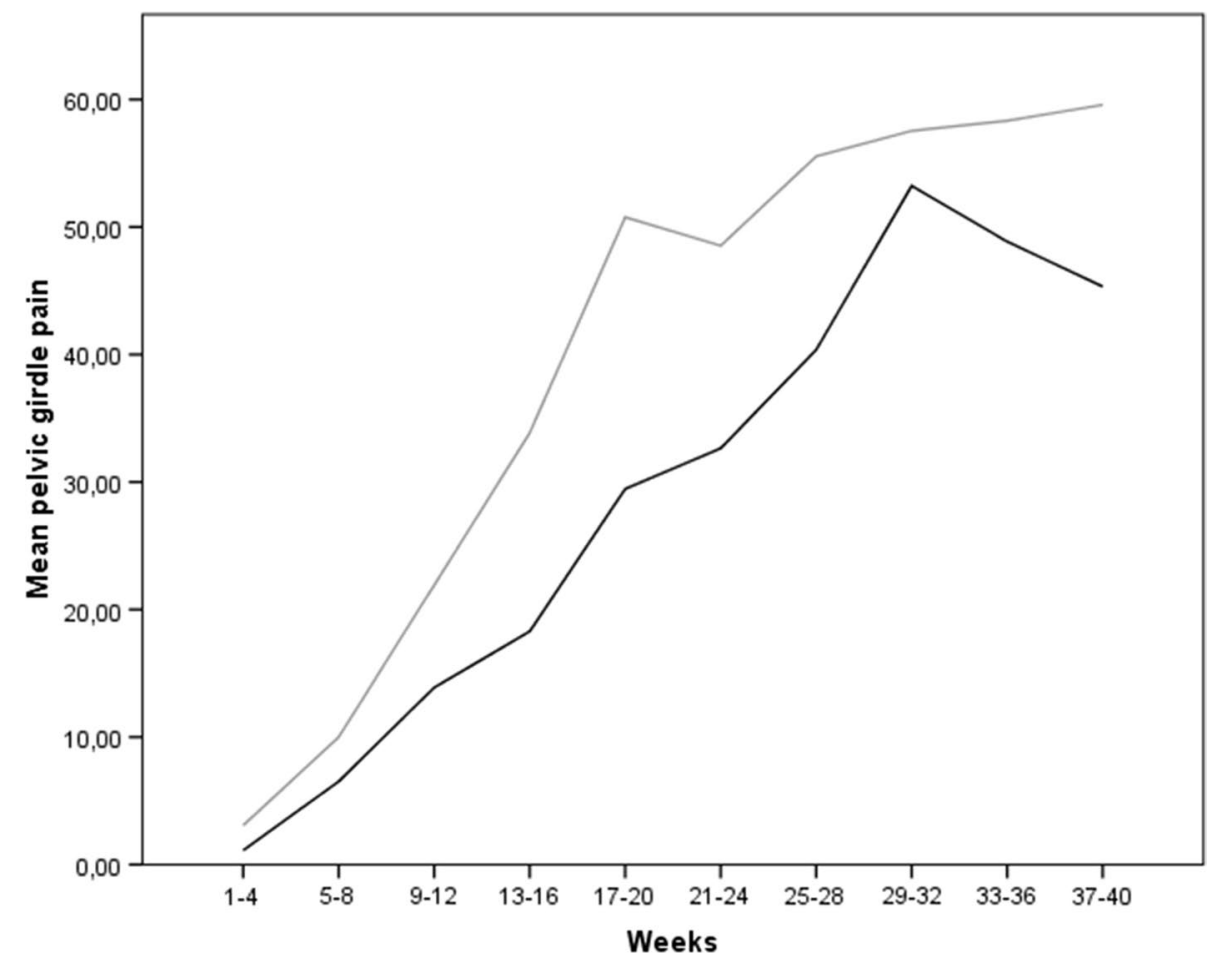

had no pain to report. Hence, the falling response rate is a weakness in our study.

A sensitivity analysis including all women with missing data in the substantial recovery group resulted in an estimate of $86 \%$ (95\% CI, 78-92) experiencing a substantial recovery within 6 weeks. Oppositely, if all the women with missing data were in the no, transitory, or incomplete recovery group, and the percentage of women with substantial recovery within 6 weeks after delivery was $67 \%$ (95\% CI, 57-76).

To describe musculoskeletal pain in the pelvic area during pregnancy the term "pelvic girdle pain" is generally preferred to "pelvic pain". This is to emphasize that the pain is not derived from the pelvic viscera, but more likely from muscles, ligaments, and joint capsules in the pelvic area [8]. We have chosen to use the term PGP in this study. However, because our data are self-reported and obtained from an SMS question, this is in conflict with the European guidelines, which specify that the PGP diagnosis needs to be verified by specific clinical tests [5]. Nevertheless, we believe that by using the term PGP we minimize confusion regarding terminology.

The SMS question was sent every Sunday, and for the SMS-track in week 1 , the answer reflected the last days of pregnancy for some women, while for others it reflected giving birth and the very first days after delivery. Because of this, the SMS-track for week 1 has not been emphasized. Also, women who delivered 1-2 weeks past the EDD, did not receive an SMS at 5-6 weeks after delivery, as the SMStrack was set to last until 6 weeks after the EDD. It is a weakness to this study that we do not have any follow-up data beyond 6 weeks after delivery.

The etiology for PGP is currently unknown, and the large variation in recovery patterns contributes to the belief that PGP is multifactorial. Pregnancy induces extensive biomechanical and hormonal changes to the female body, and a suggested theory is that PGP arises from the large, stabilizing muscles surrounding the pelvis [20]. After delivery, there is a sudden change in biomechanics and hormones, and for women with a quick recovery, this theory is therefore plausible.

We found that $17 \%$ of women reporting severe or moderate PGP the final 10 weeks of pregnancy had persistent PGP 6 weeks after delivery. In a previous study, we investigated persistent PGP in another study population, and found $16 \%$ of women reporting PP during pregnancy to have persistent PGP 3-6 months after delivery [16]. Although there are some differences between the two studies regarding study design, these findings indicate that PGP that last for more than 6 weeks may tend to become persistent. This information is important for pregnant women and pregnancy healthcare providers, and attention should be given to women with persistent PGP symptoms 6 weeks after delivery.

We found multiparity to be a risk factor for either no, transitory, or incomplete recovery from PGP 6 weeks after delivery, and although this is in line with findings from other studies investigating risk factors for PGP during pregnancy $[6,21]$, it is not an established risk factor for persistent PGP after delivery [22]. 
In a systematic review, Wuytack et al. [23] found previous LBP, overweight and obesity, a high comorbidity index, and severity of pain during pregnancy to be risk factors for persistent PGP. We found that having PGP the year before pregnancy is a risk factor for persistent PGP. In addition, our study also shows that a high pain intensity during pregnancy is a risk factor for persistent PGP 6 weeks after delivery. All the women reported increasing PGP during pregnancy, but for the women with a poor recovery, the pain intensity was higher throughout the entire pregnancy.

\section{Conclusion}

In conclusion, $83 \%$ of women with severe or moderate PGP the final 10 weeks of pregnancy experienced a subjective substantial recovery within 6 weeks after delivery. For almost half of them, the recovery occurred already within 2 weeks. This information is of interest to affected women and to pregnancy health care providers.

Acknowledgements The Norwegian Chiropractic Association (kiropraktikk.no; Storgata, Oslo, Norway) funded the acquisition of an SMSTrack license.

Funding Open access funding provided by University of Stavanger. AMG received an unconditional study grant from The Norwegian Research Foundation for Chiropractors (ELIB). For the remaining authors, none were declared.

Data availability The datasets generated during and analyzed during the current study are available from the corresponding author on reasonable request.

\section{Compliance with ethical standard}

Conflicts of interest None of the authors has any potential conflict of interest.

Ethical approval The project was registered and approved at The Norwegian National Research Ethics Committee: REK Nord 28.01.2010 with ref.nr:20107174.

Informed consent Informed consent was obtained from all individual participants included in the study.

Open Access This article is licensed under a Creative Commons Attribution 4.0 International License, which permits use, sharing, adaptation, distribution and reproduction in any medium or format, as long as you give appropriate credit to the original author(s) and the source, provide a link to the Creative Commons licence, and indicate if changes were made. The images or other third party material in this article are included in the article's Creative Commons licence, unless indicated otherwise in a credit line to the material. If material is not included in the article's Creative Commons licence and your intended use is not permitted by statutory regulation or exceeds the permitted use, you will need to obtain permission directly from the copyright holder. To view a copy of this licence, visit http://creativecommons.org/licenses/by/4.0/.

\section{References}

1. Albert HB, Godskesen M, Westergaard JG (2002) Incidence of four syndromes of pregnancy-related pelvic joint pain. Spine (Phila Pa 1976) 27:2831-2834. https://doi.org/10.1097/01. brs.0000035678.17709.1e

2. Robinson HS, Mengshoel AM, Bjelland EK, Vollestad NK (2010) Pelvic girdle pain, clinical tests and disability in late pregnancy. Man Ther 15:280-285. https://doi.org/10.1016/j. math.2010.01.006

3. Malmqvist S, Kjaermann I, Andersen K, Okland I, Bronnick K, Larsen JP (2012) Prevalence of low back and during pregnancy in a Norwegian population. J Manipulative Physiol Ther 35:272278. https://doi.org/10.1016/j.jmpt.2012.04.004

4. Wu WH, Meijer OG, Uegaki K, Mens JM, van Dieen JH, Wuisman PI, Ostgaard HC (2004) Pregnancy-related pelvic girdle pain (PPP), I: terminology, clinical presentation, and prevalence. Eur Spine J 13:575-589. https://doi.org/10.1007/s00586-003-0615-y

5. Vleeming A, Albert HB, Ostgaard HC, Sturesson B, Stuge B (2008) European guidelines for the diagnosis and treatment of pelvic girdle pain. Eur Spine J 17:794-819. https://doi.org/10.1007/ s00586-008-0602-4

6. Mogren IM, Pohjanen AI (2005) Low back pain and pelvic pain during pregnancy: prevalence and risk factors. Spine (Phila Pa 1976) 30:983-991

7. Albert H, Godskesen M, Westergaard J (2001) Prognosis in four syndromes of pregnancy-related pelvic pain. Acta Obstet Gynecol Scand 80:505-510

8. Ostgaard HC, Roos-Hansson E, Zetherstrom G (1996) Regression of back and posterior pelvic pain after pregnancy. Spine (Phila $\mathrm{Pa}$ 1976) 21:2777-2780

9. Robinson HS, Vollestad NK, Veierod MB (2014) Clinical course of pelvic girdle pain postpartum-impact of clinical findings in late pregnancy. Man Ther 19:190-196. https://doi.org/10.1016/j. math.2014.01.004

10. Bergstrom C, Persson M, Nergard KA, Mogren I (2017) Prevalence and predictors of persistent pelvic girdle pain 12 years postpartum. BMC Musculoskelet Disord 18:399. https://doi. org/10.1186/s12891-017-1760-5

11. Wuytack F, Curtis E, Begley C (2015) Experiences of firsttime mothers with persistent pelvic girdle pain after childbirth: descriptive qualitative study. Phys Ther 95:1354-1364. https:// doi.org/10.2522/ptj.20150088

12. Gutke A, Lundberg M, Ostgaard HC, Oberg B (2011) Impact of postpartum lumbopelvic pain on disability, pain intensity, healthrelated quality of life, activity level, kinesiophobia, and depressive symptoms. Eur Spine J 20:440-448. https://doi.org/10.1007/s0058 6-010-1487-6

13. Gutke A, Josefsson A, Oberg B (2007) Pelvic girdle pain and lumbar pain in relation to postpartum depressive symptoms. Spine (Phila Pa 1976) 32:1430-1436. https://doi.org/10.1097/brs.0b013 e318060a673

14. Elden H, Gutke A, Kjellby-Wendt G, Fagevik-Olsen M, Ostgaard HC (2016) Predictors and consequences of long-term pregnancyrelated pelvic girdle pain: a longitudinal follow-up study. BMC Musculoskelet Disord 17:276. https://doi.org/10.1186/s1289 1-016-1154-0

15. Mogren I (2007) Perceived health six months after delivery in women who have experienced low back pain and pelvic pain during pregnancy. Scand J Caring Sci 21:447-455. https://doi.org/1 0.1111/j.1471-6712.2006.00489.x

16. Gausel AM, Kjaermann I, Malmqvist S, Dalen I, Larsen JP, Okland I (2015) Pelvic girdle pain 3-6 months after delivery in an unselected cohort of Norwegian women. Eur Spine J. https:// doi.org/10.1007/s00586-015-3959-1 
17. Axen I, Leboeuf-Yde C (2017) "Typical” chiropractic patientscan they be described in terms of recovery patterns? Chiropr Man Therap 25:23. https://doi.org/10.1186/s12998-017-0152-0

18. Malmqvist S, Kjaermann I, Andersen K, Gausel AM, Okland I, Larsen JP, Bronnick KS (2018) Can a bothersome course of pelvic pain from mid-pregnancy to birth be predicted? A Norwegian prospective longitudinal SMS-Track study. BMJ Open 8:e021378. https://doi.org/10.1136/bmjopen-2017-021378

19. Dunn KM, Croft PR (2005) Classification of low back pain in primary care: using "bothersomeness" to identify the most severe cases. Spine (Phila Pa 1976) 30:1887-1892. https://doi. org/10.1097/01.brs.0000173900.46863.02

20. Ö HC (2007) What is pelvic girdle pain? In: A. V, V. M, R. S (eds) Movement, stability and lumbopelvic pain-integration of research and therapy. Churchill Livingstone Elsevier. p 354

21. Bjelland EK, Eskild A, Johansen R, Eberhard-Gran M (2010) Pelvic girdle pain in pregnancy: the impact of parity. Am J
Obstet Gynecol 203(146):e141-146. https://doi.org/10.1016/j. ajog.2010.03.040

22. Mogren IM (2006) BMI, pain and hyper-mobility are determinants of long-term outcome for women with low back pain and pelvic pain during pregnancy. Eur Spine J 15:1093-1102. https://doi. org/10.1007/s00586-005-0004-9

23. Wuytack F, Daly D, Curtis E, Begley C (2018) Prognostic factors for pregnancy-related pelvic girdle pain, a systematic review. Midwifery 66:70-78. https://doi.org/10.1016/j.midw.2018.07.012

Publisher's Note Springer Nature remains neutral with regard to jurisdictional claims in published maps and institutional affiliations.

\section{Affiliations}

\section{Anne Marie Gausel ${ }^{1} \cdot$ Stefan Malmqvist ${ }^{2,3} \cdot$ Knut Andersen $^{2} \cdot$ Inger Kjærmann $^{2} \cdot$ Jan Petter Larsen ${ }^{4} \cdot$ Ingvild Dalen $^{5}$. Inger Økland ${ }^{1}$}

1 Department of Obstetrics and Gynecology, Stavanger University Hospital, P.O. Box 8100, Stavanger N-4068 Stavanger, Norway

2 Department of Research, Stavanger University Hospital, Stavanger, Norway

3 Sundbybergskliniken, Sundbyberg, Sweden
4 Network for Medical Sciences, University of Stavanger, Stavanger, Norway

5 Department of Research, Section of Biostatistics, Stavanger University Hospital, Stavanger, Norway 